\title{
LAS VICEGOBERNACIONES Y VICEALCALDÍAS EN LATINOAMÉRICA*
}

\author{
Gustavo Adolfo García Arango \\ Recibido: Octubre 9 de 2015 \\ Aprobado: Noviembre 30 de 2015
}

\section{RESUMEN}

El presente artículo tuvo como objetivo realizar la revisión jurídica de la figura institucional de las vicegobernaciones y vicealcaldías en Latinoamérica. Se realizó bajo el método cualitativo con técnica documental y revisión en bases de datos jurídicas, bases de revistas indexadas y páginas oficiales de Latinoamérica. Se encontró que solo un país en Latinoamérica tiene la figura de Vicegobernador y cinco la de Vicealcaldes; que en Colombia en los últimos 20 años se han presentado cuatro proyectos fallidos en el Congreso para crear estas instituciones. En el último proyecto de Acto Legislativo presentado en el año 2013 se argumenta su creación en la necesidad de la descentralización y la reducción de costos financieros por las elecciones atípicas, situaciones que se encuentran infundadas. Se concluye que el proyecto de Acto Legislativo deja muchas cosas pendientes y que es más conveniente pensar en otras opciones menos onerosas y abiertas.

Palabras claves: Proyecto de acto legislativo, Vicealcaldías, Vicegobernaciones.

\footnotetext{
* Documento resultado de la revisión crítica de la literatura sobre el tema de las vicegobernaciones y vicealcaldías.

** Filósofo de la Universidad Pontificia Bolivariana -UPB-, abogado de la Universidad de Antioquia, Magíster en Derecho de la UPB. Docente de la Universidad de Antioquia, investigador de la Universidad Católica de Oriente, abogado de la Secretaría General del Municipio de Medellín. Correo: gustavo.garcia@medellin.gov.co.
} 


\title{
VICE GOVERNORS AND VICE MAYORS IN LATINAMERICA
}

\begin{abstract}
The aim of this article is to carry out a legal review of vicegovernors and vicemayors figures in Latin America. The methodological technique used was the qualitative method, analysis of documents, legal databases, scientific journals and websites of the Latinamerican countries.. There are vicegovernos in one country of this region and there vicegovernors in five other ones.In Colombia there have been four failure legislatives acts tto create these institutions Therefore, the last legislative act submitted in 2013, deals with its need fin order to decentralize and reduce financial cost, because of the atypical elections, situations that are unfounded.. It is concluded that the legislative act leaves many unsolved issues and it is more convenient and less expensive to propose other options.
\end{abstract}

Keywords: Legislative act project, Vicegovernors, Vicemayors.

\section{VICE GOVERNOS E VICE PREFEITURAS DA AMÉRICA LATINA}

\section{RESUMO}

Este artigo tem como objetivo realizar uma revisão legal da figura institucional dos vice governos e vice prefeituras na América Latina. $\mathrm{O}$ estudo foi realizado pelo método qualitativo com revisão técnica e documental nas bases de dados jurídicas, bancos de dados e páginas de revistas oficiais indexados na América Latina. Verificou-se que apenas um país da América Latina tem a figura do vice governador e cinco a de vice prefeitos; na Colômbia durante os últimos 20 anos se apresentaram ao Congresso quatro projetos de lei para criar essas instituições e todos eles foram vetados. No último projeto de lei apresentado em 2013, argumenta-se a necessidade da descentralização e da redução dos custos financeiros nas eleições atípicas, situações infundadas para o caso proposto. Conclui-se que o projeto de lei deixa muitas coisas pendentes e que é melhor pensar em outras opções abertas e menos onerosas.

Palavras-chave: Projeto de ato legislativo, Viceprefeituras, Vicegovernações, 


\section{INTRODUCCIÓN}

En el año 2013, se presentó en el Senado, el proyecto de Acto Legislativo 07 de 2013, por el cual se adicionaba un Capítulo V (nuevo) al Título XI de la Constitución Política de Colombia, sobre la creación de las figuras del Vicegobernador y Vicealcalde, el cual fue publicado en la Gaceta $\mathrm{N}^{\circ}$ 598/13, con ponencia de primer debate en la Gaceta $N^{\circ} 793 / 13$ :

CAPÍTULO V. Disposiciones comunes a los capítulos anteriores. Artículo 331A. A partir de los comicios de 2015 para la elección de gobernadores y alcaldes, en la misma fórmula se elegirá vicegobernador en los departamentos y vicealcalde para el Distrito Capital y los municipios capital de departamento. Cuando se presente falta temporal o absoluta del gobernador o del alcalde, el vicegobernador o el vicealcalde respectivamente lo reemplazará excepto cuando la falta absoluta se presente como consecuencia de revocatoria de mandato. Caso en el cual la revocatoria incluye al vicegobernador o vicealcalde. Las calidades, requisitos, inhabilidades, incompatibilidades, periodo y posesión de los vicegobernadores y vicealcaldes, serán los fijados por la Constitución y la ley para los gobernadores y alcaldes. El gobernador y el alcalde deberán asignar funciones al vicegobernador o vicealcalde respectivamente; estos podrán asumir cargos del nivel de gobierno territorial al que correspondan sin que esto los inhabilite para asumir llegado el caso las funciones del titular por vacancia temporal o absoluta. En caso de vacancia absoluta de los vicegobernadores o vicealcaldes, la asamblea departamental, el concejo distrital o municipal respectivamente, designarán por una sola vez su reemplazo de terna propuesta al momento de la inscripción por los candidatos. Artículo $2^{\circ}$. El presente acto legislativo regirá a partir de su promulgación.

En el mismo año, se identifica en la Gaceta Oficial el proyecto de Acto Legislativo 23 de 2013, radicado ante el Senado, con el mismo nombre del anterior proyecto.

Finalmente, ambos proyectos fueron archivos luego del primer debate en el mismo año 2013. 
No obstante, no es la primera vez que surge una propuesta para crear estas instituciones dentro del órgano ejecutivo, ya que antes se había presentado el Proyecto de Acto Legislativo No. 36 de 2005 de la Cámara de Representantes, que como se lee en la ponencia de dicho proyecto, crea la figura de los vicealcaldes y vicegobernadores para que sea el electorado el que escoja a la persona que ha de suceder en caso de faltas absolutas o temporal al Alcalde o Gobernador, terminando con el poder que tiene los superiores para nombrarlos los reemplazos en la actualidad y las elecciones por fuera del calendario electoral.

Posteriormente, en el año 2006 se había presentado proyecto para la creación de la vicealcaldía del Distrito Capital. En el año 2008 se presentó el Proyecto de Acto Legislativo 02 de 2008, en el Senado, "por el cual se modifican los artículos 303, 304,314, 323, 259 y 260, se adicionan los artículos 127 y 152 de la Constitución Política, y se dictan otras disposiciones". Para el año 2009 cursó el Proyecto de Acto Legislativo 02 de 2009, con el mismo título (Gaceta Oficial No. 590 de 2009). El proyecto de Acto Legislativo del año 2006 fue archivado por términos y los de 2008 y 2009 fueron archivados al no obtener la mayoría de votos en el primer periodo.

Aunque todos los proyectos han sido archivados, las discusiones sobre la necesidad de estas figuras en el actual sistema político colombiano sigue vigente y por ello surge la necesidad ante la actualidad, de hacer una reflexión sobre la figura de los vicegobernadores y los vicealcaldes que se constituya en materia de fuente doctrinal para futuras discusiones, dado que se ha encontrado la ausencia de material de estudio sobre el tema y, como se ha podido evidenciar, ha sido un tema recurrente en los últimos diez años en el Congreso de la República. De hecho, en la misma página del Senado, se encuentra en el sistema de prensa, que el Senador Ángel Custodia Cabrera, quien fue elegido presidente del Directorio Distrital del Partido de la U en Bogotá en marzo del año 2015, señala que uno de sus proyectos, es promover la figura del vicealcalde para Bogotá, como apoyo al Alcalde Mayor.

El trabajo tuvo como objetivo realizar la revisión jurídica de la figura institucional de las vicegobernaciones y vicealcaldía en Latinoamérica, con énfasis en Colombia.

Se realizó bajo el método cualitativo con técnica documental. Primero, se hizo una revisión en las bases jurídicas Notinet, 
Legismóvil y Artículo 20 bajo los criterios "vicealcalde, vicealcaldía, vicegobernador, vicegobernación", entre el periodo 1994-2015. Así mismo, se hizo revisión bajo estos criterios en las bases de revistas científicas Dialnet (sin resultados), Scielo (con 11 resultados con referencia a Nicaragua y Costa Rica respecto de los vicealcaldes y 84 alusiones a los vicegobernadores, en su mayoría de Argentina, pero ninguno en desarrollo de la institución como tal) y Redalyc (24 resultados). De igual modo, se hizo la revisión de las páginas oficiales de varios países latinoamericanos.

Con esta información, el artículo se estructuró en cuatro partes: una primera, en la que se hace una revisión del marco jurídico de la región latinoamericana, con la cual se pudiera tener una referencia jurídica; una segunda parte respecto de la situación de las vicealcaldías y vicegobernaciones en Colombia; una tercera, con una revisión del caso del Municipio de Medellín que cuenta con seis vicealcaldías creadas en el año 2011; y por último, las conclusiones.

\section{MARCO JURÍDICO REGIONAL}

Para poder tener una visión jurídica integral de la figura de los vicealcaldes y vicegobernadores es pertinente hacer una revisión del contexto jurídico de estas figuras en los países de la región para realizar un pequeño ejercicio de derecho comparado del cual se puedan extraer elementos que aporten al análisis jurídico del proyecto de ley en Colombia. Para ello se consultaron las páginas oficiales de México, Guatemala, Honduras, Nicaragua, El Salvador, República Dominicana, Costa Rica, Panamá, Ecuador, Perú, Bolivia, Chile, Uruguay y Paraguay.

De la revisión se observa que la figura de los vicealcaldes y de los vicegobernadores no se encuentra contemplada en la Constitución Política de los Estados Unidos Mexicanos, pero dado que ésta es una república federal, con 31 estados y un distrito federal, donde cada estado tiene la facultad jurídica para determinar su propia constitución y esquema organizacional, se revisó la constitución de los Estados de Jalisco, del Estado Libre y Soberano de Michoacán del Campo, Morelos, Nuevo León, Puebla, Veracruz y Yucatán.

En su generalidad, se observa que las ausencias temporales y permanentes de los gobernadores de cada Estado se suplen por 


\author{
nombramiento que hace el Congreso de cada Estado y con nuevas \\ elecciones populares ${ }^{1}$.
}

Por otro lado, la República Oriental de Uruguay tiene como máxima autoridad administrativa de cada gobierno departamental a los intendentes (art. 274 de la Constitución), pero no contempla una figura como la del vice o subintendente.

\title{
En la República de Paraguay "El gobierno de cada departamento será ejercido por un gobernador" (Art. 161, Constitución Nacional). Los municipios están a cargo de intendentes.
}

\section{La Constitución Política de El Salvador consagra la figura del} gobernador propietario y suplente, nombrados por el órgano ejecutivo (art. 200). Los municipios son regidos por los alcaldes que no tienen suplentes (art. 202). En igual sentido, la República de Guatemala tiene gobernadores nombrados por el Presidente y alcaldes de elección popular, sin figuras suplentes (arts. 227 y 254 ).

1 - Constitución Política del Estado de Jalisco: “ARTÍCULO 39.- En caso de falta absoluta del Gobernador del Estado, ocurrida durante los dos primeros años de su ejercicio, el Congreso procederá al nombramiento de un Gobernador interino, quien ejercerá sus funciones hasta que tome posesión el Gobernador substituto que se elija en comicios extraordinarios. La convocatoria a elección extraordinaria de Gobernador substituto se expedirá conforme las disposiciones de la Ley Electoral y tendrá lugar a más tardar, en la fecha en la que tenga verificativo la siguiente elección ordinaria para renovar el Congreso del Estado.

ARTÍCULO 40.- Cuando la falta absoluta del Gobernador del Estado ocurra en los cuatro últimos años del período respectivo, el Congreso elegirá un Gobernador substituto, quien ejercerá sus funciones hasta la terminación del mismo."

- Constitución del Estado de Morelos: "Artículo 63.- Las faltas del Gobernador hasta por sesenta días, serán cubiertas por el Secretario de Gobierno. Si la falta fuera por mayor tiempo, será cubierta por un Gobernador interino que nombrará el Congreso, y en los recesos de éste, la Diputación Permanente convocará a periodo de sesiones extraordinarias para que se haga la designación.

Artículo 64.- En caso de falta absoluta del Gobernador, ocurrida durante los tres primeros años de su ejercicio, el Congreso, con asistencia de las dos terceras partes de sus miembros, por lo menos, procederá al nombramiento de un Gobernador interino; en escrutinio secreto y por mayoría absoluta de votos, y expedirá desde luego la convocatoria respectiva para la elección del nuevo Gobernador que deba terminar el período constitucional. Artículo 65.- Cuando la falta absoluta ocurra en los tres últimos años del período respectivo, el Congreso elegirá un Gobernador substituto, quien ejercerá sus funciones hasta la terminación del mismo."

- Constitución del Estado de Nuevo León: “ARTICULO 90.- En caso de falta absoluta o imposibilidad perpetua del Gobernador dentro de los tres primeros años del período respectivo, si el Congreso estuviere reunido, será este cuerpo quien nombre, por escrutinio secreto y a mayoría absoluta de votos, un Gobernador Interino. El mismo Congreso lanzará la convocatoria para elecciones de Gobernador substituto, procurando que la fecha señalada para dichas elecciones coincida con aquella en que deban tener verificativo las de diputados a dicho Congreso, siempre que estén próximas. Pero si el Legislativo estuviere en receso, la Diputación permanente nombrará un Gobernador Interino y convocará inmediatamente al Congreso a sesiones extraordinarias para que lance la convocatoria respectiva. En el supuesto de convocarse a elecciones extraordinarias, éstas se realizarán de conformidad a lo dispuesto por la ley y bajo la dirección del órgano electoral estatal. Las controversias que en las mismas se presenten serán resueltas por el órgano previsto en el artículo 44 de esta Constitución y en las leyes relativas.

ARTICULO 910.- Si la falta absoluta o impedimento perpetuo del Gobernador acaeciera dentro de los segundos tres años del período respectivo, y el Congreso estuviere en sesiones, será éste quien nombre el Gobernador Substituto; y en caso de estar en receso, la Diputación Permanente sólo nombrará un Gobernador Interino, convocando al Congreso a sesiones extraordinarias para que éste por escrutinio secreto y a mayoría absoluta de votos, elija el Gobernador Substituto, pudiendo serlo el Interino." 
Y al igual que en El Salvador, la Constitución de la República de Panamá consagra en el artículo 252 un Gobernador y su suplente para cada Provincia, de libre nombramiento y remoción por parte del Gobierno Central.

En Guatemala, el Código Municipal dispone sobre las funciones del Concejo: "b) Los concejales sustituirán, en su orden, al alcalde en caso de ausencia temporal, teniendo el derecho a devengar una remuneración equivalente al sueldo del alcalde cuando ello suceda" (art. 54). Así mismo, contempla la figura de las alcaldías comunitarias o alcaldías auxiliares (art. 56), como enlace entre las comunidades y el gobierno municipal.

También, en El Salvador, es función del concejo municipal, la cual preside el Alcalde, escoger entre sus miembros el sustituto del alcalde: "25) designar de su seno al miembro que deba sustituir al Alcalde, Síndico o Regidor en caso de ausencia temporal o definitiva" (art. 30). Y el artículo 49 lo ratifica al disponer que "Los concejales sustituirán, en su orden, al alcalde en caso de ausencia temporal, teniendo el derecho a devengar una remuneración equivalente al sueldo del alcalde cuando ello suceda" (Constitución Política).

En Paraguay, por la Ley Orgánica Municipal -Ley 3966 de 2010-, los intendentes, que son los representantes administrativos de la municipalidad, son sustituidos por el presidente de la Junta Municipal en caso de ausencias temporales o de manera transitoria en de vacancia definitiva, caso en el cual se deben realizar nuevas elecciones (art. 53).

No obstante, sí aparecen algunas figuras relacionadas con los vice en otros países del continente.

Por ejemplo, en la Ley Orgánica Municipal del Estado de Jalisco, el artículo 11 considera la figura del vicepresidente del ayuntamiento en los siguientes términos:

Artículo 11.- Los ayuntamientos de cada Municipio del Estado se integrarán por un Presidente, un Vicepresidente y el número de regidores de mayoría relativa y de representación proporcional que se determinan en el artículo siguiente, quienes serán electos, popular y directamente mediante planillas; permanecerán en sus cargos tres años y se renovarán en su totalidad al final de cada período. 
Esta norma contempla un capítulo para el Vicepresidente Municipal (arts. 41-45), en donde se dispone que es elegido entre los regidores (art. 41) y que le corresponde suplir al Presidente Municipal en sus ausencias temporales (art. 42). Y la falta del vicepresidente es suplida por los ediles propietarios del cabildo (art. 77, cfr. Art. 18).

La Constitución de Honduras establece los departamentos y los municipios pero sin señalar las autoridades, lo cual es suplido por el Decreto Número 134-90, Ley de Municipalidades y del Régimen Político, expedido por el Congreso Nacional, en donde se estipula en el artículo $5^{\circ}$ que "El Gobernador Departamental será del libre nombramiento y remoción del Poder Ejecutivo. En caso de ausencia mayor de cinco días, lo sustituirá el Alcalde de la Cabecera Departamental." Esta ley en el artículo $26^{\circ}$ sobre la Corporación Municipal señala que se conformará por un Alcalde, un Vice Alcalde y un número de regidores que dependiente del número de habitantes. Concretamente, respecto del Vice Alcalde estipula en este artículo:

Al partido político que ganare la Alcaldía le corresponderá el Vice Alcalde. El Vice Alcalde gozará de los mismos derechos de los Regidores, con voz y sin voto, y la ausencia de los Regidores será cubierta de acuerdo como manda la Ley, salvo en el caso de ejercer la titularidad que llega a gozar de todos los privilegios.

Sobre la primera función del Vice Alcalde es la sustitución:
ARTÍCULO 41.- (Según reforma por Decreto 127-2000) En caso de que vacara el Alcalde lo sustituirá el Vice Alcalde, en el caso de los Regidores su sustitución se hará conforme lo establece la Ley Electoral y de las Organizaciones Políticas. Si vacaren el Alcalde y el Vice Alcalde, corresponderá a la Organización Política que los hubiere propuesto, efectuar la sustitución respectiva, por conducto de la Directiva Central.

El artículo 45 determina: "En ausencia o incapacidad del Alcalde lo sustituirá el Vice Alcalde (...) El Vice Alcalde devengará el sueldo que le asigne la Corporación Municipal y cumplirá las funciones que le delegue el Alcalde Municipal. El salario que se le asigne al Vice Alcalde no deberá ser menor que el que devengan los Regidores de tiempo completo." 
Además, en el artículo 31-A se dispone: "El Alcalde, o en su defecto el Vice Alcalde convocará y presidirá las sesiones de la Corporación."

La Constitución de la República de Nicaragua también consagra la figura del vice alcalde y hace alusión a él en los siguientes términos:

Artículo178.- El Alcalde, el Vice-Alcalde y los Concejales serán elegidos por el pueblo mediante el sufragio universal, igual, directo, libre y secreto, de conformidad con la ley. Serán electos Alcalde y Vice-Alcalde, los candidatos que obtengan la mayoría relativa de los votos. Los Concejales serán electos por representación proporcional, de acuerdo con el cociente electoral. El Alcalde y el Vice-Alcalde sólo podrán ser reelectos por un período. La reelección del Alcalde y Vice-Alcalde no podrá ser para el período inmediato siguiente.

De igual modo, la República de Panamá también consagra en su Constitución la figura del Vicealcalde: "ARTICULO 241. Habrá en cada distrito un Alcalde, Jefe de la Administración Municipal, y un Vicealcalde, electos por votación popular directa para un periodo de cinco años."

La República del Ecuador sí contempla la figura de los vice para varios niveles:

Art. 252.- Cada provincia tendrá un consejo provincial con sede en su capital, que estará integrado por una prefecta o prefecto y una viceprefecta o viceprefecto elegidos por votación popular; por alcaldesas o alcaldes, o concejalas o concejales en representación de los cantones; y por representantes elegidos de entre quienes presidan las juntas parroquiales rurales, de acuerdo con la ley.

La prefecta o prefecto será la máxima autoridad administrativa, que presidirá el Consejo con voto dirimente, y en su ausencia temporal o definitiva será reemplazado por la persona que ejerza la viceprefectura, elegida por votación popular en binomio con la prefecta o prefecto.

Art. 253.- Cada cantón tendrá un concejo cantonal, que estará integrado por la alcaldesa o alcalde y las concejalas 
y concejales elegidos por votación popular, entre quienes se elegirá una vicealcaldesa o vicealcalde.

Art. 251.- Cada región autónoma elegirá por votación a su consejo regional y a su gobernadora o gobernador regional, que lo presidirá y tendrá voto dirimente. Los consejeros regionales se elegirán de forma proporcional a la población urbana y rural por un período de cuatro años, y entre ellos se elegirá una vicegobernadora o vicegobernador. (Constitución)

En el Estado Plurinacional de Bolivia, el gobierno autónomo departamental está dirigido por la Gobernadora o el Gobernador (art. 279, Constitución Política). Y el gobierno autónomo municipal tiene un órgano ejecutivo presidido por el alcalde (art. 283, Constitución).

En caso de renuncia o muerte, inhabilidad permanente o revocatoria de la máxima autoridad ejecutiva de un gobierno autónomo, se procederá a una nueva elección, siempre y cuando no hubiere transcurrido la mitad de su mandato. En caso contrario, la sustituta o sustituto será una autoridad ya electa definida de acuerdo al Estatuto Autonómico o Carta Orgánica según corresponda. (Art. 286)

La República Dominicana cuenta con la Ley No. 176-07 del Distrito Nacional y los Municipios, la cual dispone que cada municipio tendrá un gobierno con dos órganos: el concejo municipal (normativo, reglamentario y de fiscalización) y la sindicatura, que es el órgano ejecutivo.

Conforme lo dispone esta ley, cada ayuntamiento cuenta con un vicesíndico que se elige en la misma fecha y forma que el síndico y por el mismo periodo (art. 65), el cual tiene entre sus funciones realizar las actividades que el síndico le confiera, como representarlo en las sesiones del concejo (art. 62) o sustituirlo en casos de ausencia temporal o definitiva (art. 63, 64, 66).

Revisada la literatura sobre el tema, se encontró un artículo relacionado con la representación femenina en Costa Rica donde se cataloga a las "vicealcaldesas" y "vicealcaldes" como "cargos decorativos" (Blanco, 2005, p. 58), dado que para el momento no existía la figura en la 
estructura institucional y se le asignaba ese nombre de manera informal a las denominadas alcaldías suplentes (p. 65-66).

No obstante, en la actualidad, en Costa Rica se encuentra la figura de dos vicealcaldes. Para el caso, la Ley No. 8765 de agosto de 2009, Código Electoral, en el artículo 310 modificó el artículo 14 del Código Municipal ( $\left.\mathrm{N}^{\circ} 7794\right)$, el cual contempla la figura de los vicealcaldes en los siguientes términos:

Denominase alcalde municipal al funcionario ejecutivo indicado en el artículo 169 de la Constitución Política. Existirán dos vicealcaldes municipales: un(a) vicealcalde primero y un(a) vicealcalde segundo. El (la) vicealcalde primero realizará las funciones administrativas y operativas que el alcalde titular le asigne; además, sustituirá, de pleno derecho, al alcalde municipal en sus ausencias temporales y definitivas, con las mismas responsabilidades y competencias de este durante el plazo de la sustitución.

En los casos en que el o la vicealcalde primero no pueda sustituir al alcalde, en sus ausencias temporales $y$ definitivas, el o la vicealcalde segundo sustituirá al alcalde, de pleno derecho, con las mismas responsabilidades y competencias de este durante el plazo de la sustitución.

(

Todos los cargos de elección popular a nivel municipal que contemple el ordenamiento jurídico serán elegidos popularmente...

Para el caso de Costa Rica, como se evidencia en el artículo Alfaro y Gómez $(2012,119)$, tanto para el año 2006 como para finales del año 2010 se nombraron 162 vicealcaldes.

De esta manera, se observa que siete países de los revisados (México, Guatemala, El Salvador, Paraguay, Uruguay, Chile y Perú) no poseen la institución del vicealcalde, cinco sí lo poseen con diferentes formas de elección (Honduras, Nicaragua, Costa Rica, Panamá y República Dominicana).

Por su parte, Ecuador es el único país que tiene vicegobernadores, mientras que El Salvador y Panamá tienen gobernadores suplentes. 


\section{ELMARCOJURÍDICO COLOMBIANO}

Teniendo como marco de discusión la exposición de motivos del proyecto de Acto Legislativo 07 de 2013, se encuentra que se fundamenta básicamente en dos supuestos: el de la descentralización y los costos para el Estado por nuevas elecciones.

\subsection{Descentralización}

En la exposición de motivos de este proyecto, se expresa que el país siempre ha tenido un desarrollo político centralista, vertical, favoreciendo el Gobierno Nacional, situación que cedió un poco con la elección popular de alcaldes desde 1986 y con el modelo de política descentralizada que trajo la Constitución de 1991, pero aun así, se considera que se ha impedido un desarrollo legal de la autonomía territorial.

En cuanto a la descentralización y la autonomía de las entidades territoriales basta con decir que este principio se concreta en la actualidad con la elección popular de los gobernadores y alcaldes cuando existe la vacancia definitiva del cargo; y que la reforma constitucional no soluciona de fondo la situación planteada, toda vez que el proyecto solo contempla los vicealcaldes para las ciudades capitales de Departamento.

Para el caso de las vacancias definitivas de los alcaldes por incapacidad física permanente (art. 101, Ley 136 de 1994), destitución (art. 104), ausencia forzada (109) o suspensión disciplinaria (105) el Gobernador es quien designará a quien deba reemplazarlo del mismo movimiento y filiación política del titular, de terna que para el efecto presente el movimiento al cual pertenezca el alcalde en el momento de la elección (art. 106).

Cuando la ausencia sea temporal (con excepción de la suspensión), el alcalde es quien encargará de funciones a uno de sus secretarios, conforme lo dispone el art. 06 de la Ley 136 de 1994.

De igual modo, se considera que dicha propuesta se enmarca dentro del principio de descentralización administrativa contemplado en la Constitución Política, cuando se establece que "Colombia es un Estado social de derecho, organizado en forma de República unitaria, descentralizada, con autonomía de sus entidades territoriales, democrática, participativa y pluralista" (art. 1, CP). 


\subsection{Costos financieros}

En la exposición de motivos, luego de mencionar una revisión de los datos sobre elecciones atípicas consultados en la página de la Registraduría General, entre el periodo 2013 a 2012 (363 elecciones atípicas de alcaldes y 15 de gobernadores), se dice que estos procesos "demandan un despliegue institucional y financiero por parte del Estado que resultan costosos para la democracia." La exposición de motivos sobre las elecciones atípicas parte de un marco social y político negativo: la corrupción que permea todos los niveles del Estado pero que es más evidente en el nivel territorial por el contacto directo con los ciudadanos; mandatarios involucrados con grupos armados al margen de la ley, sancionados con suspensión o destitución, asesinados y financiación de campañas con recursos de dudosa procedencia; todo ello genera encargos y elecciones atípicas que permiten prácticas clientelistas.

Respecto de los costos financieros, debe tenerse en cuenta que Colombia cuenta con 32 departamentos, con sus respectivas capitales, para un total de 64 vicegobernadores y vicealcaldes.

Haciendo referencia a los costos generados para el Estado la convocatoria y elección de un nuevo gobernador, se consultó la página de la Registraduría General de la Nación, como lo menciona la exposición de motivos.

Allí se observa que entre marzo de 2003 y agosto de 2013 van 18 elecciones atípicas de gobernador. De las 18, sólo cinco fueron por nulidad de elecciones y cuatro relacionados con procesos sancionatorios. El resto por vencimiento del periodo o por muerte.

En términos financieros habría que sopesar el costo de nueve elecciones de gobernadores en un periodo de diez años contra los costos salariales y demás (como gastos de vehículo, conductor, secretaria, viáticos y gastos conexos al cargo) de 32 vicegobernadores por todo un año, por los mismos diez años.

Y para el caso de los alcaldes se registran 346 elecciones atípicas, por terminación del periodo del mandatario anterior, es decir, no por causas de destitución ni muerte del alcalde anterior que permitiera obviar el proceso electoral, sino que por el contrario, se generan al terminarse el periodo de elección del anterior. 
Solo de este análisis podría llegarse a la conclusión de la inconveniencia de la reforma constitucional para la creación de la figura de los vicegobernadores.

Respecto de la corrupción y el clientelismo que se presenta ante la ausencia definitiva de alcaldes y gobernadores, señalado en la exposición de motivos como situaciones "que enrumban al Estado en un desfile de prácticas clientelistas", también se ha advertido que puede pasar con las figuras de los vicealcaldes y vicegobernadores, al correr el riesgo de que estos cargos queden sometidos a arreglos políticos para rotarse las alcaldías, desvirtuando la figura y poniendo en riesgo los intereses de la democracia.

En general, el proyecto de acto legislativo deja pendientes:

- La inscripción de una terna de vicealcaldes al momento de inscripción por parte de los candidatos.

- Configuración de inhabilidad por parte de los vicegobernadores y vicealcaldes que asumen funciones del principal en el caso de las vacancias temporales, para efectos de ser candidatos en posteriores elecciones.

- No se determina si es posible que el vicegobernador o vicealcalde pueda asumir la secretaría de algún despacho o dirección de una entidad descentralizada o cualquier otro cargo de libre nombramiento y remoción.

- Cómo se procede en caso de ausencia definitiva del vicegobernador o vicealcalde.

- No define posición jurídica respecto de los alcaldes menores del Distrito Capital.

- No se observa en la exposición de motivos el impacto fiscal ni hay cifras que confirmen la hipótesis señalada en relación a que sería menos oneroso para el Estado la creación del vicegobernador y vicealcalde que los procesos de elección atípicas.

- Tampoco se considera que en época de campaña se hacen acuerdos políticos de conveniencia que una vez posesionados pueden terminar en oposición, generando divisiones y enfrentamientos que 
perjudicarían la ejecución de los programas de desarrollo y políticos que se haya fijado y por el cual votaron los ciudadanos.

\subsection{Alternativas}

Basta mirar las discusiones que se han generado sobre la figura del vicepresidente en el país, para tener un reflejo de las situaciones que se presentarán a nivel territorial con unas figuras ambiguas en las funciones, que terminan generando más cuestionamientos que comentarios a favor, no solo en la actualidad sino desde varios momentos.

Pero si lo que se desea es reducir los gastos que involucran las elecciones de alcaldes por vacancia del cargo sin terminar el periodo de elección, considerando la revisión latinoamericana, se sugiere considerar como otras opciones:

- Que, como en los Estados Mexicanos, sea el máximo órgano de la entidad el que escoja el sucesor, de una terna que presente el partido político del gobernante anterior, para que termine el respectivo periodo de mandato.

- La posibilidad de que sea el partido político el que elija al sucesor.

- Sea el Presidente del Concejo el que supla el cargo.

- Sea un miembro del concejo del mismo partido político del alcalde anterior el que asuma dicha.

- A parte de las anteriores, continúa el llamado a nuevas elecciones, en aplicación del principio

En conclusión, se considera que es más conveniente pensar en otras opciones, igualmente válidas pero menos onerosas y abiertas, que podrían lograr el mismo objetivo del proyecto.

\section{EL CASO DEL MUNICIPIO DE MEDELLÍN}

Dado que en el Municipio de Medellín existe la figura de los Secretarios Vicealcaldes, sería obvio pensar que a esta entidad territorial le tocaría defender la figura que se piensa crear con el proyecto de ley para ser consecuentes con la estructura definida en el Decreto con fuerza de 
Acuerdo 1364 de 2012, "Por el cual se adopta la Estructura de la Administración Municipal, se definen las funciones de sus organismos y dependencias, se crean y modifican unas entidades descentralizadas y se dictan otras disposiciones", subrogado casi en su totalidad, por el Decreto con fuerza de Acuerdo 883 de 2015, por el cual se adecuó la estructura municipal, a raíz del ajuste al Plan de Ordenamiento Territorial-POT-, y la declaración de Conglomerado Público, realizada por el Alcalde de la ciudad en noviembre de 2014, norma en la cual se conservó la institución de las vicealcaldías.

Sin embargo, eso no es así y la confusión que se pueda generar queda en lo meramente conceptual, porque si bien Medellín cuenta con seis vicealcaldías $^{2}$ y el proyecto de acto legislativo crea esta figura, la naturaleza jurídica, el objeto, las funciones y la estructura orgánica son completamente distintas.

Respecto de la naturaleza jurídica, mientras el proyecto de acto legislativo propone la creación de un cargo de elección popular, en Medellín son cargos de libre nombramiento y remoción.

En relación con el objeto, la figura del vicealcalde en el proyecto de acto legislativo es creada para reemplazar en las faltas temporales y absolutas a los alcaldes.

En Medellín, conforme el Decreto Municipal 883 de 2015, las Vicealcaldías son "las que dirigen, orientan, coordinan y articulan los sectores de desarrollo administrativo de la gestión municipal." (Art. 21) No es el objeto la suplencia del Alcalde en sus faltas temporales o absolutas sino que tienen por objeto: "dirigir, formular y evaluar el Plan Estratégico Sectorial de Desarrollo Administrativo, del sector que coordina", así como su articulación con el Plan de Desarrollo Municipal y el Plan Ordenamiento Territorial, y coordinar la adopción de las políticas generales de su sector, entre otras funciones (art. 22, Decreto Municipal 883 de 2015).

En este sentido, tampoco hay identidad entre la figura del vicealcalde del proyecto de acto legislativo y el Municipio de Medellín.

2 Las vicealcaldías creadas por el Decreto Municipal con fuerza de acuerdo 1364 de 2012 son: 1) Secretaría Vicealcaldía de Educación, Cultura, Participación, Recreación y Deporte; 2) Secretaría Vicealcaldía de Salud, Inclusión y Familia; 3) Secretaría Vicealcaldía de Gobernabilidad, Seguridad y Servicio a la Ciudadanía; 4) Secretaría Vicealcaldía de Hábitat, Movilidad, Infraestructura y Sostenibilidad; 5) Secretaría Vicealcaldía de Ciencia, Tecnología e Innovación, Desarrollo Económico, Internacionalización y Alianzas Público Privadas 6) Secretaría Vicealcaldía de Gestión Territorial. Estas dependencias se conservaron en el ajuste a la estructura de la Administración Municipal surtido mediante el Decreto con fuerza de Acuerdo 883 de 2015. 
En cuanto a las funciones, conforme el proyecto, el Alcalde es quien puede asignar funciones o encargos al vicealcalde, situación que no le inhabilita para asumir las funciones posteriores como Alcalde por vacancia temporal o absoluta del titular. Sin embargo, no señala cuáles pueden ser esas funciones y si puede implicar el nombramiento en cargos de libre nombramiento y remoción.

Por el contrario, los vicealcaldes en el Municipio de Medellín tuvieron sus funciones establecidas en el art. 23 del Decreto Municipal 1364 de 2012, en la actualidad bajo el art. 22 del Decreto Municipal 883 de 2015. Funciones definidas y establecidas previamente, a diferencia del proyecto de acto legislativo.

En último lugar, el proyecto de acto legislativo no ubica a la vicealcaldía en ninguna parte de la estructura orgánica del nivel municipal. De hecho, de manera vaga y abierta, se da a entender que el Alcalde sería quien le asigne las funciones al vicealcalde, mientras que el Municipio de Medellín, luego de una concienzuda discusión en el marco de la modernización municipal, y considerando el Decreto Nacional 785 de 2005, por el cual se establece el sistema de nomenclatura y clasificación de funciones de los empleos de las entidades territoriales, además de la asesoría del Departamento Administrativo de la Función Pública, consideró la figura de los vicealcaldes como secretarios de despacho, dándole a cada uno una ubicación concreta en el organigrama municipal, asignando áreas concretas, así como dependencias y entidades descentralizadas que se articulan a ella.

\section{CONCLUSIONES}

En conclusión, en la región, solo el Ecuador cuenta con la figura constitucional del vicegobernador, mientras que El Salvador y Panamá cuentan con la figura del Gobernador Suplente.

Por otro lado, Honduras, Nicaragua, Costa Rica, Panamá y República Dominicana sí consagran la figura del Vice Alcalde o su equivalente. En Honduras, es elegido por el partido político que gane la alcaldía; en Ecuador, escogido por y entre los miembros del concejo; en Nicaragua, Costa Rica y Panamá es de elección popular.

Ni México ni Guatemala ni El Salvador ni Paraguay ni Uruguay ni Chile ni Perú contemplan la figura de un vicealcalde. 
A nivel de Colombia, en los últimos 20 años, se han presentado cuatro proyectos en el Congreso que no han pasado, lo que evidencia las dudas que se ciernen sobre estas figuras políticas.

La exposición de motivos, al hacer referencia a los costos de elecciones atípicas por alcaldes inhabilitados y sancionados se queda sin piso, porque en su gran mayoría son por vencimiento del periodo.

El último proyecto de acto legislativo deja cosas pendientes:

Solo se crean vicealcaldes para las ciudades capitales, dejando más de 1066 municipios sin vicealcaldes, lo que evidencia el poco impacto que tendría la reforma constitucional en relación a lo que se busca en la exposición de motivos. No aclara la inscripción de la terna de candidatos, el tema de inhabilidades, nombramientos en cargos de libre nombramiento y remoción, cómo se procede en caso de ausencia definitiva del vicegobernador o vicealcalde, no define posición jurídica respecto de los alcaldes menores del Distrito Capital, no hay cifras que verifiquen el impacto fiscal ni pronunciamiento alguno sobre los acuerdos políticos.

Igualmente, se concluye que si lo que se desea es reducir los gastos que involucran las elecciones de alcaldes por vacancia del cargo sin terminar el periodo de elección, considerando la revisión latinoamericana, se considera que es más conveniente pensar en otras opciones, igualmente válidas pero menos onerosas y abiertas, que podrían lograr el mismo objetivo del proyecto.

\section{REFERENCIAS BIBLIOGRÁFICAS}

Alfaro Redondo, R. \& Gómez Campos, S. (2012). Costa Rica: Reconfiguración política en un contexto de gobierno dividido. Revista de Ciencia Política (Cr), vol. 32 (1),pp. 109-128.

Blanco Lizano, R. (2005). Representación femenina legislativa y municipal en el 2002. El valor de las cuotas y la trampa de las vicealcaldías. Revista de Ciencias Sociales (Cr), vol. III-IV (109-110), pp. 57-68.

Cámara de Representantes de la República de Colombia (2005). Proyecto de Acto Legislativo No. 36 de 2005, "Por medio del cual se modifican los artículos 314, 308 y se adiciona el artículo 323 de la Constitución Política de Colombia" 
Estado de Jalisco, Estados Unidos Mexicanos (1917). Constitución Política.

Estado de Jalisco, Estados Unidos Mexicanos (1984). Ley Orgánica Municipal.

Estado de Morelos, Estados Unidos Mexicanos (1930). Constitución Política.

Estado de Nuevo León, Estados Unidos Mexicanos (1917). Constitución Política.

Estado Plurinacional de Bolivia (2009). Constitución Política.

Municipio de Medellín (2012). Decreto con fuerza de Acuerdo 1364 de 2012, "Por el cual se adopta la Estructura de la Administración Municipal, se definen las funciones de sus organismos y dependencias, se crean y modifican unas entidades descentralizadas y se dictan otras disposiciones".

Municipio de Medellín (2015). Decreto con Fuerza de Acuerdo 883, "Por el cual se adecúa la estructura de la Administración Municipal, las funciones de sus organismos, dependencias y entidades descentralizadas, se modifican unas entidades descentralizadas y se dictan otras disposiciones."

Registraduría General de la Nación (2014). Elecciones atípicas de Gobernador 2003 - 2013. Recuperado de: http://www.regis traduria.gov.co/-Historico-de-elecciones-atipicas-.html.

República de Colombia (1994). Ley 136 de 1994.

República de Costa Rica (2009). Ley No. 8765 de 2009, Código Electoral

República de Ecuador (2008). Constitución Política.

República de El Salvador (1983). Constitución.

República de Guatemala(1985). Constitución Política.

República de Guatemala (2012). Decreto 12-2012, Código Municipal. 
República de Honduras (1982). Constitución.

República de Honduras (1990). Decreto Número 134-90, Ley de Municipalidades y del Régimen Político.

República de Nicaragua (1948). Constitución.

República de Panamá (1972). Constitución Política.

República de Paraguay (2010). Ley 3966 de 2010, Ley Orgánica Municipal.

República Dominicana (2007). Ley No. 176-07 del Distrito Nacional y los Municipios

República Dominicana (2010). Constitución Política.

República Oriental de Uruguay (1967). Constitución Política.

Senado de la República de Colombia (2008). Proyecto de Acto Legislativo 02 de 2008, "por el cual se modifican los artículos 303, 304,314, 323, 259 y 260, se adicionan los artículos 127 y 152 de la Constitución Política, y se dictan otras disposiciones".

Senado de la República de Colombia (2009). Proyecto de Acto Legislativo 02 de 2009, "por el cual se modifican los artículos 303, 304,314, 323, 259 y 260, se adicionan los artículos 127 y 152 de la Constitución Política, y se dictan otras disposiciones".

Senado de la República de Colombia (2013). Proyecto de Acto Legislativo $\mathrm{N}^{\circ} .07$ de 2013, "Por el cual se adiciona un capítulo 5 (Nuevo) al título XI de la Constitución Política de Colombia"

Senado de la República de Colombia (2013). Proyecto de Acto Legislativo $\mathrm{N}^{\circ} .23$ de 2013, "Por el cual se adiciona un Capítulo 5 (nuevo) al Título XI de la Constitución Política de Colombia." 